CLINICAL STUDY

\title{
Identification of TPIT and other novel autoantigens in lymphocytic hypophysitis; immunoscreening of a pituitary cDNA library and development of immunoprecipitation assays
}

\author{
Casey Jo Anne Smith ${ }^{1,2}$, Sophie Bensing ${ }^{2,3}$, Christine Burns ${ }^{4}$, Phillip J Robinson ${ }^{5}$, Anna A Kasperlik-Zaluska ${ }^{6}$, \\ Rodney J Scott ${ }^{4,7}$, Olle Kämpe ${ }^{2}$ and Patricia A Crock ${ }^{1}$ \\ ${ }^{1}$ Department of Paediatric Endocrinology and Diabetes, Faculty of Health, Locked Bag 1, Newcastle Mail Centre, John Hunter Children's Hospital, \\ University of Newcastle, Newcastle 2310, New South Wales, Australia, ${ }^{2}$ Department of Medical Sciences, Uppsala University, Uppsala, Sweden, \\ ${ }^{3}$ Department of Molecular Medicine and Surgery, Karolinska Institutet, Stockholm, Sweden, ${ }^{4}$ Division of Genetics, Hunter Area Pathology Service, \\ John Hunter Hospital, Newcastle, New South Wales, Australia, ${ }^{5}$ Cell Signalling Unit, Children's Medical Research Institute, Westmead, New South Wales, \\ Australia, ${ }^{6}$ Department of Endocrinology, Centre for Postgraduate Medical Education, Bielanski Hospital, Warsaw, Poland and ${ }^{7}$ Discipline of Medical \\ Genetics, Faculty of Health, University of Newcastle, and the Hunter Medical Research Institute, New Lambton Heights, Newcastle, New South Wales, \\ Australia
}

(Correspondence should be addressed to P A Crock; Email: patricia.crock@newcastle.edu.au)

\begin{abstract}
Background: Lymphocytic hypophysitis is an organ-specific autoimmune disease of the pituitary gland. A specific and sensitive serological test currently does not exist to aid in the diagnosis.

Objective: To identify target autoantigens in lymphocytic hypophysitis and develop a diagnostic assay for these proteins.

Design/methods: A pituitary cDNA expression library was immunoscreened using sera from four patients with lymphocytic hypophysitis. Relevant cDNA clones from screening, along with previously identified autoantigens pituitary gland-specific factor 1a and 2 (PGSF1a and PGSF2) and neuronspecific enolase (NSE) were tested in an in vitro transcription and translation immunoprecipitation assay. The corticotroph-specific transcription factor, TPIT, was investigated separately as a candidate autoantigen.

Results: Significantly positive autoantibody reactivity against TPIT was found in 9/86 hypophysitis patients vs $1 / 90$ controls $(P=0.018)$. The reactivity against TPIT was not specific for lymphocytic hypophysitis with autoantibodies detectable in the sera from patients with other autoimmune endocrine diseases. Autoantibodies were also detected against chromodomain-helicase-DNA binding protein 8 , presynaptic cytomatrix protein (piccolo), $\mathrm{Ca}^{2+}$-dependent secretion activator, PGSF2 and NSE in serum samples from patients with lymphocytic hypophysitis, but at a frequency that did not differ from healthy controls. Importantly, 8/86 patients with lymphocytic hypophysitis had autoantibodies against any two autoantigens in comparison with $0 / 90$ controls $(P=0.0093)$.

Conclusions: TPIT, a corticotroph-specific transcription factor, was identified as a target autoantigen in $10.5 \%$ of patients with lymphocytic hypophysitis. Further autoantigens related to vesicle processing were also identified as potential autoantigens with different immunoreactivity patterns in patients and controls.
\end{abstract}

European Journal of Endocrinology 166 391-398

\section{Introduction}

Lymphocytic hypophysitis is part of the spectrum of organ-specific autoimmune endocrine diseases and is characterised by the infiltration of self-reactive T-lymphocytes into the pituitary gland. The disease is more frequently seen in females than males at a ratio of 6:1 and has a striking association with pregnancy (1). In the acute phase, patients usually present with headaches and visual disturbances due to an upwardly expanding pituitary mass that mimics an adenoma (2). Corticotrophs are often the first cell type to be affected, in contrast to pituitary adenoma where they are usually the last to fail $(3,4,5)$. The ensuing secondary adrenal insufficiency is potentially fatal. In chronic cases, the ongoing autoimmune process can cause postinflammatory fibrosis leading to pituitary gland atrophy and an empty sella syndrome $(6,7,8)$.

The pituitary mass in lymphocytic hypophysitis can be indistinguishable from that of a pituitary adenoma on MRI. Pituitary biopsy has been used to both alleviate the symptoms of the pituitary mass and to diagnose the disease on histological grounds. Pituitary biopsy can, however, lead to permanent pituitary failure and 
therefore a conservative approach using corticosteroids to reduce the size of the mass has been recommended in suspected cases.

High-titre autoantibodies are a characteristic feature of many autoimmune diseases. They can often be detected years before the onset of the disease and can be good predictors of disease progression and outcome $(9,10)$. Pituitary autoantibodies have been studied in various autoimmune diseases by a number of techniques including immunofluorescence (IF) $(11,12,13$, 14, 15), immunoblotting (16) and more recently immune screening of cDNA expression libraries followed by radioligand immunoprecipitation assay (17) to identify the autoantigens targeted. Indirect IF has the potential to detect autoantibodies to as yet uncharacterised autoantigens, although the method is probably not sensitive enough in many cases (1). Immunoblotting recognises linear epitopes and identifies autoantigens by molecular weight (16) but not cellular localisation (as in IF), whereas immunoprecipitation requires a tertiary structure.

A number of potential autoantigens have been proposed in lymphocytic hypophysitis including $\alpha$-enolase $(18,19,20)$, neuron-specific enolase (NSE) (20), GH $(21,22)$, pituitary gland-specific factors 1a and 2 (PGSF1a and PGSF2) (17), secretogranin II (23) and most recently chromosome 14 open reading frame 166 and chorionic somatomammotropin (24). Although some are undoubtedly markers of an underlying autoimmune process, they are not always specific to pituitary disease. The major target autoantigens in lymphocytic hypophysitis remain unknown.

This study aimed to identify potential target autoantigens in lymphocytic hypophysitis by screening a pituitary cDNA expression library. The cDNA clones identified by sera from patients with lymphocytic hypophysitis were subsequently evaluated using in vitro transcription and translation (ITT) followed by immunoprecipitation with patient and healthy control serum. We also tested the previously identified pituitary autoantigens NSE, PGFS1a, PGFS2 and a potential novel candidate, TPIT, a pituitary-specific transcription factor essential for development of the corticotroph lineage $(25,26)$.

\section{Methods}

\section{Patients}

Serum samples were collected for analysis from 86 patients with lymphocytic hypophysitis, including 21 biopsy-proven patients and 65 suspected cases of lymphocytic hypophysitis. The suspected cases were further sub-classified into groups consisting of 43 patients with 'suspected lymphocytic hypophysitis', ten patients with isolated ACTH deficiency, six patients with lymphocytic hypophysitis that had progressed to empty sella, two patients with isolated ACTH deficiency and an empty sella and four patients with diabetes insipidus (neuro-infundibulo-hypophysitis). In the spectrum of suspected cases, the diagnosis was considered likely by the referring endocrinologist, usually on the basis of clinical history, examination and MRI scan appearance. Serum samples were also obtained from 144 patients with other autoimmune endocrine diseases comprising 14 patients with Addison's disease, 20 with autoimmune polyendocrine syndrome type 1 (APS1), 20 with Graves' disease, 20 with Hashimoto's thyroiditis, and 20 with type 1 diabetes mellitus. A separate group of 50 patients with isolated ACTH deficiency was also used for comparison. This latter group has been investigated extensively (27). Serum samples collected from 90 healthy Australian blood donors served as controls in all experiments.

Ethical approval was obtained from the Committee of Ethics, Faculty of Medicine, Uppsala University, the Human Research Ethics Committees of the Hunter Area Health Service and University of Newcastle (9706183.13) and the Australian Red Cross Blood Bank Ethics Committee, with informed, written consent from all patients and controls.

\section{Immunoscreening of a human pituitary cDNA library}

Serum samples from four patients with lymphocytic hypophysitis (one biopsy proven and three suspected cases) were chosen for immunoscreening of a pituitary cDNA expression library on the basis of high-titre pituitary autoantibodies detected by an immunoblotting assay of pituitary cytosolic proteins (4) and a classical clinical history. The pituitary cDNA expression library (28) was immunoscreened separately with all four patient sera (diluted 1:200) as described previously (29). In vitro excision of the pBK-CMV phagemid vectors from the ZAP express library vector was performed according to the manufacturer's instructions (Stratagene, La Jolla, CA, USA). The isolated cDNA clones were partially sequenced using a dye-terminator sequencing kit (Amersham Pharmacia Biotech) and ABI 3730 sequencer (Perkin Elmer Applied Biosystems, Foster City, CA, USA). cDNA clones were identified by comparison of the sequencing data against available databases using BLAST.

\section{Potential candidate autoantigens}

The corticotroph-specific transcription factor, TPIT (also referred to as T-box 19) has been identified as the causative gene in isolated ACTH deficiency of neonatal onset. Hence, it was chosen for study as corticotroph cells tend to be preferentially targeted in lymphocytic hypophysitis resulting in isolated ACTH deficiency. A full-length cDNA TPIT clone was kindly donated by Dr Jacques Drouin (Montreal, Canada). 


\section{Previously reported candidate autoantigens}

Full-length cDNA clones PGSF1a and PGSF2 were kindly donated by Dr Ke-ita Tatsumi (Japan) and NSE was purchased from the clone database (Image Clone 3629603).

\section{ITT of autoantigens and immunoprecipitation}

All library cDNA clones identified by immunoscreening that were of interest, as well as TPIT, PGSF1a, PGSF2 and NSE, were subcloned into the pTNT vector (Promega) by double-restriction-enzyme digestion for improved efficiency of ITT. Inserts were re-verified by sequencing as above. A full-length clone encoding rat $\mathrm{Ca}^{2+}$-dependent secretion activator (rCADPS) protein was kindly provided by Dr Tom Martin (Michigan), which was also subcloned into the pTNT vector.

Autoantigens were expressed using an ITT assay to determine the frequency and specificity of immunoreactivity against these proteins. Recombinant ${ }^{35}$ S-radiolabelled proteins were produced by ITT in an Sp6 Quick coupled reticulocyte lysate system (Promega) and used for immunoprecipitation with patient sera as described previously (30). The patient serum from which the respective cDNA clone was isolated by immunoscreening the pituitary cDNA library was used as the positive control and 4\% BSA (Sigma) was used as the negative control. Positive and negative controls were run in triplicate, whereas all other sera were analysed in duplicate. Results were expressed as an antibody index (c.p.m. sample/mean c.p.m. of healthy controls). The upper normal autoantibody index was set at the mean of the unequivocally negative healthy blood donors plus 3 s.D. for all autoantigens tested.

\section{Statistical analysis}

A $\chi^{2}$-test was performed to determine the probability of analysed autoantigens as significant target autoantigens in lymphocytic hypophysitis. Yates' correction was applied due to consistently small group sizes. A $P$ value of $<0.05$ was considered significant.

\section{Results}

\section{Isolation and identification of potential autoantigens from immunoscreening of a pituitary CDNA library}

A pituitary cDNA expression library was immunoscreened with sera from four patients with lymphocytic hypophysitis: one biopsy proven and three suspected cases, previously shown to have high-titre pituitary autoantibodies on immunoblotting (4). A total of 58 individual cDNA clones were isolated and partially sequenced. A single cDNA clone encoding
chromodomain-helicase-DNA binding protein 8 (CHD8) was independently identified on separate screenings by two different patients' sera. On comparison with the GenBank database (GenBank accession NM_020920.2), the partial cDNA sequence isolated from the library from both patients was found to encode the carboxyl-terminal region of the 2302 amino acid, $260 \mathrm{kDa}$ CHD8 protein. The recombinant protein produced by ITT was efficiently immunoprecipitated by the two screening sera and hence was selected for additional analyses.

From the remaining cDNA clones, a subset with interesting functional characteristics was chosen for testing with ITT. When transcribed and translated into the immunoprecipitation assay system, most of the recombinant proteins were recognised solely by the screening serum or no sera at all. Two proteins encoding Piccolo (presynaptic cytomatrix protein) and CADPS were each immunoprecipitated by the screening serum as well as additional lymphocytic hypophysitis patients, but not by any of the healthy controls and therefore were selected for further investigation.

Two cDNA clones isolated from the biopsy-proven patient sera used for immunoscreening encoded a small portion of the $5^{\prime}$ end of the piccolo gene, the full length of which is reported to encode a 5142 amino acid protein, with a 4935 amino acids transcript variant also being identified (GenBank accessions NM_033026.4 and NM_014510.2 respectively).

Three transcript variants for the human CADPS gene located on chromosome 3p14.2 have been reported to differ in the $3^{\prime}$ nucleotide sequence of the gene. When compared with the GenBank mRNA reference sequences (variant 1: accession ID NM_003716, variant 2: accession ID NM_183394 and variant 3: accession ID NM_183393) the partial cDNA clone encoding CADPS extracted from the pituitary library matches the entire sequence of all three variants from nucleotide position 951 (the end of exon 4). The $\mathrm{N}$-terminal protein sequence is crucial for correct protein folding of the CADPS protein, therefore a full-length rCADPS was obtained and used for all further analyses. The rat homologue is located on chromosome 15p16 and shares 98\% homology with human CADPS protein.

\section{Autoantibody analysis of library autoantigens CHD8, piccolo and $\mathrm{rCADPS}$}

To ascertain the specificity of CHD8, piccolo and rCADPS (full length) as autoantigens, ${ }^{35}$ S-methioninelabelled proteins were immunoprecipitated against sera from 86 patients with lymphocytic hypophysitis and 90 healthy blood donors (Table 1).

CHD8 autoantibodies were detected in the sera from seven of the $86(8.14 \%)$ patients with lymphocytic hypophysitis including two of the $21(9.52 \%)$ patients with biopsy-proven disease, four of the $43(9.30 \%)$ 
Table 1 Immunoreactivity specificity against lymphocytic hypophysitis candidate autoantigens.

\begin{tabular}{lccc}
\hline & \multicolumn{2}{c}{ Autoantibody (positive/total (\%)) } & \\
\cline { 2 - 3 } & $\begin{array}{c}\text { Lymphocytic } \\
\text { hypophysitis }\end{array}$ & Healthy controls & \multirow{2}{*}{$\boldsymbol{P}^{*}$} \\
\hline Tutoantigen & $9 / 86(10.47)$ & $1 / 90(1.11)$ & $0.0186^{\dagger}$ \\
CHD8 & $7 / 86(8.14)$ & $3 / 90(2.22)$ & 0.2932 \\
Piccolo & $3 / 86(3.49)$ & $2 / 90(2.22)$ & 0.9563 \\
CADPS & $12 / 86(13.95)$ & $11 / 90(12.22)$ & 0.9058 \\
PGSF2 & $5 / 86(5.81)$ & $2 / 90(2.22)$ & 0.4048 \\
NSE & $2 / 86(2.33)$ & $0 / 90(0.00)$ & 0.4571 \\
Any 2 AutoAg & $8 / 86(9.30)$ & $0 / 90(0.00)$ & $0.0093^{\dagger}$ \\
\hline
\end{tabular}

${ }^{*}$ Calculated by $\chi^{2}$-test with Yates' correction, ${ }^{\dagger} P<0.05$.

suspected cases and in one of the four (25\%) patients with suspected hypophysitis with diabetes insipidus as the single presenting symptom. Positive immunoreactivity was also observed in three of the $90(3.33 \%)$ healthy controls (Supplementary Figure 1, see section on supplementary data given at the end of this article, panel A). The frequency of autoantibodies in lymphocytic hypophysitis patients was not significantly different from healthy controls, $P=0.2932\left(\chi^{2}\right.$-test with Yates' correction).

Piccolo autoantibodies were found in three of the 86 (3.49\%) patients with lymphocytic hypophysitis comprising one of the $21(4.76 \%)$ biopsy-proven patients, one of the $43(2.33 \%)$ patients with suspected lymphocytic hypophysitis and a single patient of ten (10.0\%) with isolated ACTH deficiency. Autoantibodies were also detected in two of the $90(2.22 \%)$ healthy controls, of which one had extremely high-titre autoantibodies in comparison with the control screening serum (Supplementary Figure 1, panel B).

Low-titre autoantibodies against the recombinant rCADPS protein were identified in the sera of 12 of the $86(14 \%)$ lymphocytic hypophysitis patients. Of these 12, three were biopsy proven cases (three of $21,14.3 \%$ ), six were suspected hypophysitis (six of 43 , $14 \%$ ), and single cases with isolated ACTH deficiency (one of ten, $10 \%$ ), empty sella as a late stage of hypophysitis (one of six, 16.7\%) and isolated ACTH deficiency with empty sella (one of two, $50 \%$ ). None of the four patients with diabetes insipidus had these autoantibodies. However, a similar frequency of CADPS autoantibodies was also observed in healthy controls with 11 of the $90(12.2 \%)$ considered positive (Supplementary Figure 1, panel C).

\section{Potential candidate autoantigen TPIT}

A positive autoantibody index was seen against TPIT in nine of the $86(10.5 \%)$ patients with lymphocytic hypophysitis. These included one of the $21(4.76 \%)$ biopsy-proven patients, four of the $43(9.30 \%)$ patients with suspected lymphocytic hypophysitis, one of the ten $(10.0 \%)$ patients with ACTH deficiency, one of the six $(16.7 \%)$ patients with empty sella and two of the four $(50 \%)$ patients with diabetes insipidus. Immunoreactivity was only detected in one of the 90 (1.11\%) healthy controls (Fig. 1). Patients with lymphocytic hypophysitis had a significantly higher frequency of autoantibodies against TPIT than that of healthy controls, $P=0.0186$ ( $\chi^{2}$-test with Yates' correction).

To determine whether TPIT autoantibodies were specific for lymphocytic hypophysitis, the autoantibody status of patients with other autoimmune endocrine diseases was investigated. Autoantibodies against TPIT were detected in the serum from two patients with Addison's disease, one patient with APS1, one patient with Graves' disease, two patients with Hashimoto's thyroiditis, one type 1 diabetes patient (six of the 94 patients vs nine of the 86 patients with hypophysitis, $P=0.47$ ( $\chi^{2}$-test with Yates' correction) (Fig. 1).

Two of the fifty patients with isolated ACTH deficiency had TPIT autoantibodies (Fig. 1).

\section{Previously reported candidate autoantigens}

The frequency and specificity of autoantibodies in lymphocytic hypophysitis sera were also determined with the previously described pituitary autoantigens PGSF1a, PGSF2 and NSE against the panel of 86 patients with lymphocytic hypophysitis and 90 healthy blood donors (Table 1).

Insufficient ${ }^{35} \mathrm{~S}$-methionine incorporation was obtained with PGSF1a despite subcloning into the pTNT vector. Therefore, no immunoprecipitation experiments were conducted with this autoantigen.

PGSF2 autoantibodies were detected in the sera of two of the $21(9.52 \%)$ biopsy-proven patients, one of the $43(2.33 \%)$ suspected cases, one of the six $(16.7 \%)$ patients with empty sella and one of the four $(25 \%)$ patients with diabetes insipidus compared with two of

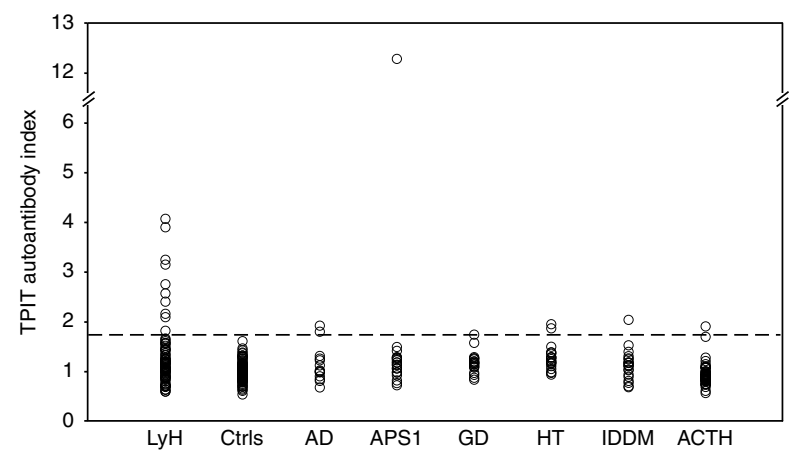

Figure 1 Analysis of autoantibodies against TPIT in sera from patients with lymphocytic hypophysitis ( $\mathrm{LyH} ; n=86)$, healthy controls (Ctrls; $n=80$ ), Addison's disease (AD; $n=14$ ), APS1 $(n=20)$, Graves' disease (GD; $n=20)$, Hashimoto's thyroiditis (HT; $n=20$ ), type 1 diabetes mellitus (IDDM; $n=20$ ) and isolated ACTH deficiency (ACTH; $n=50)$. The broken line indicates the upper limit of the normal range calculated by the average autoantibody index of the negative healthy controls plus 3 s.D. (limit $=1.62$ ). 
the $90(2.22 \%)$ healthy blood donors (Supplementary Figure 1, panel D). The difference was not statistically significant.

Autoantibodies were found against the NSE recombinant protein in two of the $86(2.33 \%)$ patients with lymphocytic hypophysitis, one patient (one of the six, $16.7 \%$ ) with empty sella and a single patient (one of the two, 50\%) with empty sella syndrome combined with isolated ACTH deficiency. No autoantibodies against NSE were detected in the sera from healthy controls (Supplementary Figure 1, panel E).

\section{Patients with multiple autoantibody reactivity}

In addition, eight of the 86 patients with lymphocytic hypophysitis had positive autoantibodies against two autoantigens in comparison to none of the 90 controls, $P=0.0093$ ( $\chi^{2}$-test with Yates' correction). Two patients (one biopsy proven and one 'suspected') had positive immunoreactivity to both CHD8 and PGSF2. Two further patients (one biopsy-proven case and one patient with diabetes insipidus) had a positive autoantibody index for CHD8 and TPIT. A single biopsy-proven patient had both piccolo and CADPS autoantibodies, while a 'suspected' lymphocytic hypophysitis patient showed immunoreactivity against CHD8 and CADPS. A patient diagnosed with empty sella syndrome had autoantibodies against TPIT and NSE and a further patient with empty sella syndrome and isolated ACTH deficiency was positive for CADPS and NSE autoantibodies. None of the healthy controls with immunoreactivity were positive for more than a single autoantigen.

\section{Discussion}

This study identified TPIT as a minor target autoantigen in lymphocytic hypophysitis when tested in an immunoprecipitation assay. A number of other potential autoantigens were found, including CHD8 (a DNAbinding protein), Piccolo (a presynaptic cytomatrix protein associated with the active zone) and a CADPS. These proteins are involved in vesicle processing that is fundamental to pituitary peptide hormone release.

The transcription factor TPIT was chosen as a candidate pituitary autoantigen as it is essential for the terminal differentiation of pituitary pro-opiomelanocortin-expressing cells and is cell specific $(25,26)$. Corticotrophs are often the first cell type to be affected in lymphocytic hypophysitis and some cases of isolated ACTH deficiency are probably autoimmune $(4,27)$. Mutations in the TPIT gene cause neonatal isolated ACTH deficiency $(25,26,31)$. TPIT was identified as a significant autoantigen in $10.5 \%$ of patients with hypophysitis. So far, from our data, we could not link TPIT reactivity to specific clinical subtypes of hypophysitis. Interestingly, autoantibodies were not only confined to those patients with isolated ACTH deficiency but were also detected in two patients with diabetes insipidus as the presenting symptom of presumed infundibuloneurohypophysitis. In one patient, MRI scan showed stalk thickening and enlargement of the anterior pituitary with uniform enhancement. Diabetes insipidus has been associated with vasopressin cell antibodies in the hypothalamus using IF $(14,32)$. TPIT autoantibodies were also detected in patients with other autoimmune endocrine diseases and hence may not be specific for lymphocytic hypophysitis. It cannot be assumed that TPIT autoantibodies are non-specific in this setting as coexistent hypophysitis has been described at autopsy in patients with Addison's disease and up to $10 \%$ of patients with Hashimoto's thyroiditis have been shown to have pituitary antibodies by ELISA (33) and IF (34). Although a transcription factor as an autoantigen appears counterintuitive and the mechanism of autoantibody formation is not known, there is a precedent in SOX9 and SOX10 found in vitiligo (35). Recently, autoantibodies to the pituitary transcription factor PiT-1, detected by immunoblotting and antibody-specific ELISA, have been described in patients with late onset hypopituitarism and polyglandular autoimmunity (36). Interestingly, mutations in both TPIT and PiT-1 give rise to hypopituitarism, i.e. monogenic disorders that can be mimicked by acquired autoimmune hypophysitis.

CHD8 was isolated independently by the sera from two patients with suspected lymphocytic hypophysitis on immunoscreening of the pituitary library. Given the rarity of this disorder, this would be an amazing coincidence; therefore, the protein was considered a strong candidate as a pituitary autoantigen. The protein is a chromatin remodelling ATPase of the SNF2 family, that regulates gene expression. Its specific role is to bind p53 and suppress its function, thereby acting as an antiapoptotic factor (37). Autoantibodies were detected in an additional five patients with lymphocytic hypophysitis (two biopsy proven); however they were not significantly more frequent than in healthy controls.

The secretion of hormones, neurotransmitters and peptides from neurons, neuroendocrine and endocrine cells is regulated by the $\mathrm{Ca}^{2+}$-dependent fusion of secretory vesicles with the plasma membrane $(38,39)$. Two types of secretory vesicles, small clear synaptic vesicles and large dense-core vesicles, are essential to the secretion process of packaging, docking, priming and fusion. This is a fundamental route for the secretion of pituitary peptide hormones in the pituitary, the disruption of which could lead to hormonal insufficiencies. Secretogranin II, which is involved in this process, has previously been isolated from screening of the same pituitary library used in this study (23). The protein is abundantly expressed in gonadotrophs, thyrotrophs and corticotrophs (40) and is believed to mediate the packaging or sorting of peptide hormones and neuropeptides into granules of neuroendocrine cells and the 
vesicles of selected neurons (41). In this study, we have isolated and identified two further candidate autoantigens, CADPS and piccolo, both related to vesicle processing.

Piccolo is a presynaptic cytomatrix protein associated with the active zone of neurons and neuroendocrine cells (42), which is a specialised region where synaptic vesicles dock and fuse to release neurotransmitter. piccolo and bassoon (a homologous protein) function as tethering proteins that mediate efficient synaptic vesicle clustering but do not directly participate in neurotransmitter release (43). In particular, piccolo functions as a $\mathrm{Ca}^{2+}$ sensor in exocytosis of this process (44). Autoantibodies against piccolo were detected in $8 \%$ of patients with lymphocytic hypophysitis; however, this was not statistically different from controls. The reason for the extremely high titre in one healthy control is unexplained.

CADPS plays a fundamental role in the $\mathrm{Ca}^{2+}$. regulated exocytosis of dense-core vesicles in neuroendocrine cells and in the secretion of a subset of neurotransmitters $(45,46)$. The protein is a phosphatidylinositol 4,5-bisphosphate $\left(\mathrm{PIP}_{2}\right)$-binding protein that acts after vesicle docking and priming (47), yet before calcium-triggered fusion and facilitates large dense-core vesicle exocytosis (48). Northern blot analysis has confirmed mRNA expression of CADPS in the pituitary (47). The CADPS isolated from the pituitary library did not possess the $5^{\prime}$ end of the gene sequence, essential for the correct folding of the protein. Immunoreactivity to rCADPS was detected at a similar frequency in both lymphocytic hypophysitis patients and healthy controls.

We have also confirmed that a minority of patients with lymphocytic hypophysitis have autoantibodies against PGSF2. Immunoreactivity against this protein was previously reported in a small number of patients with lymphocytic hypophysitis, isolated ACTH deficiency, idiopathic TSH deficiency and other autoimmune diseases. Tanaka et al. (17) also reported immunoreactivity against the pituitary-specific protein PGSF1a in a similar cohort of patients. Immunoreactivity against this protein has since been detected at a high frequency in patients with rheumatoid arthritis, suggesting it is more likely to be an autoantigen in rheumatoid arthritis than lymphocytic hypophysitis (49).

$\alpha$-Enolase antibodies in lymphocytic hypophysitis have been well studied by immunoblotting (19) and ITT and immunoprecipitation techniques (18). Autoantibodies are believed to be more of a prognostic marker of autoimmunity itself rather than a specific diagnostic marker. Lymphocytic hypophysitis patient serum has also been shown to recognise the $\gamma$ isoform of the enolase protein, NSE, on immunoblotting (20). In this study, autoantibodies were only detected in four patients, with patient sera previously positive on immunoblotting, not positive in the ITT system.
This highlights the hazards of comparing results across different assays.

ITT and immunoprecipitation have been employed to analyse many autoantigens across multiple autoimmune diseases. It has the advantage over other techniques of high-affinity autoantibodies recognising three-dimensional conformational epitopes of the expressed autoantigen, rather than the linear epitopes of denatured proteins as with immunoblotting. The method also provides a quantitative analysis of high-throughput samples, with only small amounts of both protein and serum sample required. However, immunoprecipitation is not achievable with all proteins. Adequate protein levels may not be produced in some instances, as in the case of PGSF1a, and additionally autoantibodies may not recognise the autoantigen when not in its native in vivo form. Indeed with CHD8 and piccolo, addition of DTT was required for effective immunoprecipitation with the patient sera. Finally, the results of ITT with NSE as an autoantigen were totally different from those with the immunoblotting technique. Alternative techniques and approaches may therefore be required to validate results in certain cases.

There are several ongoing challenges in this field. The anterior pituitary has five hormone-secreting cell types, each of which could have their own specific target autoantigen(s) and whose autoimmune destruction may present a different clinical picture. Our data show that even immunoreactivity to a cell-specific transcription factor, TPIT, is neither confined to isolated ACTH deficiency, nor does it seem completely hypophysitis specific. Secondly, we have identified several proteins involved in vesicle trafficking as potential autoantigens. Finally, as no control serum recognised more than one protein, we suggest that a panel of target autoantigens be developed and reactivity patterns be compared across different clinical scenarios of autoimmune hypophysitis. Even then, it may not be possible to differentiate the different types of hypophysitis on the basis of autoantibodies alone.

We have identified TPIT as a minor autoantigen in lymphocytic hypophysitis, using a candidate approach. We have also shown that immunoscreening of a pituitary cDNA expression library is an effective way of identifying candidate autoantigens in lymphocytic hypophysitis, with ITT and subsequent immunoprecipitation assays being a valuable method for their evaluation. While the major autoantigen(s) were not identified, re-screening with additional patient sera holds the potential for isolating major autoantigens and the development of an essential serological test for lymphocytic hypophysitis.

\section{Supplementary data}

This is linked to the online version of the paper at http://dx.doi.org/10. 1530/EJE-11-1015. 


\section{Declaration of interest}

The authors declare that there is no conflict of interest that could be perceived as prejudicing the impartiality of the research reported.

\section{Funding}

This study was supported by NH\&MRC Grant 100952, NH\&MRC PhD scholarship to C J A Smith, The Hunter Children's Research Foundation, The John Hunter Charitable Trust and HMRI (Hunter Medical Research Institute), the Swedish Research Council, the Torsten and Ragnar Söderberg Foundation, the Lisa and Johan Grönberg Foundation, Tore Nilsson Foundation for Medical Research the Lars Hierta Memorial Foundation, the Swedish Society for Medical Research and Uppsala University and Grant 501-2-1-07-23/09 CMKP (Poland) to A A Kasperlik-Zaluska.

\section{Acknowledgements}

We thank Dr Jacques Drouin, Dr Tom Martin and Dr Ke-ita Tatsumi for their generous donation of cDNA plasmids for our research. We also thank Åsa Hallgren for invaluable technical assistance. We are grateful to the many endocrinologists who referred sera: Dr A Platts from Albury; Dr W Braund, Dr P Phillips, Dr S Stranks and Dr G Wittert from Adelaide; Dr R Cuneo, Prof. M D’Embden, Dr M Kaamp, Dr R Mortimer, Dr A Morton and Dr A Russell from Brisbane: Dr P Davoren from the Gold Coast; Dr J Burgess and Dr T Greenway from Hobart; Dr F Alford, Dr R Arnott, Prof. P Colman, Prof. M Cooper, Prof. P Ebeling, Dr D Engler, Dr M Gonzalez, Dr S Hamblin, Prof. L Harrison, Dr D Healey, Dr A Hunter, Dr J O’Day, Dr W Plehwe, Dr D Topliss, Dr Yeo and Dr M Zacharin from Melbourne; Dr D Anderson, Dr M Epstein, Dr J Fowler, Dr B King, Dr G Major, Dr S McGrath and Prof. R Smith from Newcastle; Dr L Green, Dr D Hurley, Dr G Price and Dr Peter Pullan from Perth; Dr A Basci, Dr R Chen, Dr D Chipps, Prof. D Chisolm, Dr J Marks, Prof. M McLean, Dr A McElduff, Dr K Samaras, Dr J Steil, Dr C Strakosh and Dr M Sulway from Sydney, Australia; Dr S Asa and Dr S Ezzat from Canada; Dr Delahunt Dr R Donald, Prof. E Espiner and Dr J Liversey from New Zealand; Prof. A Grossman and Prof. S Shalet from the United Kingdom. We thank Prof. Dr. D K Lüdecke, pituitary neurosurgeon, for constructive comments on the manuscript.

\section{References}

1 Caturegli P, Newschaffer C, Olivi A, Pomper MG, Burger PC \& Rose NR. Autoimmune hypophysitis. Endocrine Reviews 200526 599-614. (doi:10.1210/er.2004-0011)

2 Thodou E, Asa SL, Kontogeorgos G, Kovacs K, Horvath E \& Ezzat S. Lymphocytic hypophysitis: clinicopathological findings. Journal of Clinical Endocrinology and Metabolism 199580 2302-2311. (doi:10.1210/jc.80.8.2302)

3 Bensing S, Kasperlik-Zaluska AA, Czarnocka B, Crock PA \& Hulting A. Autoantibodies against pituitary proteins in patients with adrenocorticotropin-deficiency. European Journal of Clinical Investigation 200535 126-132. (doi:10.1111/j.1365-2362. 2005.01459.x)

4 Crock PA. Cytosolic autoantigens in lymphocytic hypophysitis. Journal of Clinical Endocrinology and Metabolism $1998 \mathbf{8 3}$ 609-618. (doi:10.1210/jc.83.2.609)

5 Jensen MD, Handwerger BS, Scheithauer BW, Carpenter PC, Mirakian R \& Banks PM. Lymphocytic hypophysitis with isolated corticotropin deficiency. Annals of Internal Medicine 1986105 200-203.

6 Hashimoto K, Yamakita N, Ikeda T, Matsuhisa T, Kuwayama A, Sano T \& Yasuda K. Longitudinal study of patients with idiopathic isolated TSH deficiency: possible progression of pituitary dysfunction in lymphocytic adenohypophysitis. Endocrine Journal 200653 593-601. (doi:10.1507/endocrj.K06-055)
7 Ishihara T, Hino M, Kurahachi H, Kobayashi H, Kajikawa M, Moridera K, Ikekubo K \& Hattori N. Long-term clinical course of two cases of lymphocytic adenohypophysitis. Endocrine Journal 199643 433-440. (doi:10.1507/endocrj.43.433)

8 Powrie JK, Powell M, Ayers AB, Lowy C \& Sonksen PH. Lymphocytic adenohypophysitis: magnetic resonance imaging features of two new cases and a review of the literature. Clinical Endocrinology 199542 315-322. (doi:10.1111/j.1365-2265. 1995.tb01881.x)

9 Bizzaro N. Autoantibodies as predictors of disease: the clinical and experimental evidence. Autoimmunity Reviews 2007 6 325-333. (doi:10.1016/j.autrev.2007.01.006)

10 Scofield RH. Autoantibodies as predictors of disease. Lancet 2004 363 1544-1546. (doi:10.1016/S0140-6736(04)16154-0)

11 Gluck M \& Scherbaum WA. Substrate specificity for the detection of autoantibodies to anterior pituitary cells in human sera. Hormone and Metabolic Research 199022 541-545. (doi:10.1055/ s-2007-1004967)

12 Gluck M, Schrell U \& Scherbaum WA. Reactivity and intracellular location of the ACTH cell autoantigen in human fetal and adult anterior pituitary tissue. Autoimmunity $1993 \quad 14$ 299-305. (doi:10.3109/08916939309079232)

13 Pouplard A, Bottazzo GF, Doniach D \& Roitt IM. Binding of human immunoglobulins to pituitary ACTH cells. Nature 1976 261 142-144. (doi:10.1038/261142a0)

14 Scherbaum WA \& Bottazzo GF. Autoantibodies to vasopressin cells in idiopathic diabetes insipidus: evidence for an autoimmune variant. Lancet 19831 897-901. (doi:10.1016/S0140-6736(83) 91328-4)

15 Scherbaum WA, Schrell U, Gluck M, Fahlbusch R \& Pfeiffer EF. Autoantibodies to pituitary corticotropin-producing cells: possible marker for unfavourable outcome after pituitary microsurgery for Cushing's disease. Lancet 19871 1394-1398. (doi:10.1016/ S0140-6736(87)90592-7)

16 Crock P, Salvi M, Miller A, Wall J \& Guyda H. Detection of anti-pituitary autoantibodies by immunoblotting. Journal of Immunological Methods 1993162 31-40. (doi:10.1016/00221759(93)90404-U)

17 Tanaka S, Tatsumi KI, Kimura M, Takano T, Murakami Y, Takao T, Hashimoto K, Kato Y \& Amino N. Detection of autoantibodies against the pituitary-specific proteins in patients with lymphocytic hypophysitis. European Journal of Endocrinology 2002147 767-775. (doi:10.1530/eje.0.1470767)

18 Tanaka S, Tatsumi KI, Takano T, Murakami Y, Takao T, Yamakita N, Tahara S, Teramoto A, Hashimoto K, Kato Y \& Amino N. Anti-alpha-enolase antibodies in pituitary disease. Endocrine Journal 200350 697-702. (doi:10.1507/endocrj.50. 697)

19 O'Dwyer DT, Smith AI, Matthew ML, Andronicos NM, Ranson M, Robinson PJ \& Crock PA. Identification of the 49-kDa autoantigen associated with lymphocytic hypophysitis as alpha-enolase. Journal of Clinical Endocrinology and Metabolism $2002 \mathbf{8 7}$ 752-757. (doi:10.1210/jc.87.2.752)

20 O'Dwyer DT, Clifton V, Hall A, Smith R, Robinson PJ \& Crock PA. Pituitary autoantibodies in lymphocytic hypophysitis target both gamma- and alpha-Enolase - a link with pregnancy? Archives of Physiology and Biochemistry 2002110 94-98. (doi:10.1076/ apab.110.1.94.897)

21 Takao T, Nanamiya W, Matsumoto R, Asaba K, Okabayashi T \& Hashimoto K. Antipituitary antibodies in patients with lymphocytic hypophysitis. Hormone Research 200155 288-292. (doi:10. $1159 / 000050015)$

22 Kikuchi T, Yabe S, Kanda T \& Kobayashi I. Antipituitary antibodies as pathogenetic factors in patients with pituitary disorders. Endocrine Journal 200047 407-416. (doi:10.1507/endocrj.47. 407)

23 Bensing S, Hulting AL, Hoog A, Ericson K \& Kämpe O. Lymphocytic hypophysitis: report of two biopsy-proven cases and one suspected case with pituitary autoantibodies. Journal of Endocrinological Investigation 200730 153-162. 
24 Lupi I, Broman KW, Tzou SC, Gutenberg A, Martino E \& Caturegli P. Novel autoantigens in autoimmune hypophysitis. Clinical Endocrinology 200869 269-278. (doi:10.1111/j.13652265.2008.03180.x)

25 Lamolet B, Pulichino AM, Lamonerie T, Gauthier Y, Brue T, Enjalbert A \& Drouin J. A pituitary cell-restricted T box factor, Tpit, activates POMC transcription in cooperation with Pitx homeoproteins. Cell 2001104 849-859. (doi:10.1016/S0092-8674 (01)00282-3)

26 Pulichino AM, Vallette-Kasic S, Tsai JP, Couture C, Gauthier Y \& Drouin J. Tpit determines alternate fates during pituitary cell differentiation. Genes and Development 200317 738-747. (doi:10. 1101/gad.1065703)

27 Kasperlik-Zaluska AA, Czarnocka B \& Czech W. Autoimmunity as the most frequent cause of idiopathic secondary adrenal insufficiency: report of 111 cases. Autoimmunity $2003 \mathbf{3 6}$ 155-159. (doi:10.1080/0891693031000095871)

28 Bensing S, Fetissov SO, Mulder J, Perheentupa J, Gustafsson J, Husebye ES, Oscarson M, Ekwall O, Crock PA, Hökfelt T, Hulting AL \& Kämpe O. Pituitary autoantibodies in autoimmune polyendocrine syndrome type 1. PNAS $2007 \mathbf{1 0 4} 949-954$. (doi:10.1073/pnas.0610070104)

29 Rorsman F, Husebye ES, Winqvist O, Björk E, Karlsson FA \& Kämpe O. Aromatic-L-amino-acid decarboxylase, a pyridoxal phosphate-dependent enzyme, is a beta-cell autoantigen. PNAS 199592 8626-8629. (doi:10.1073/pnas.92.19.8626)

30 Husebye ES, Gebre-Medhin G, Tuomi T, Perheentupa J, LandinOlsson M, Gustafsson J, Rorsman F \& Kämpe O. Autoantibodies against aromatic L-amino acid decarboxylase in autoimmune polyendocrine syndrome type I. Journal of Clinical Endocrinology and Metabolism 199782 147-150. (doi:10.1210/jc.82.1.147)

31 Vallette-Kasic S, Brue T, Pulichino AM, Gueydan M, Barlier A, David M, Nicolino M, Malpuech G, Dechelotte P, Deal C, Van Vliet G, De Vroede M, Riepe FG, Partsch CJ, Sippell WG, Berberoglu M, Atasay B, de Zegher F, Beckers D, Kyllo J, Donohoue P, Fassnacht M, Hahner S, Allolio B, Noordam C, Dunkel L, Hero M, Pigeon B, Weill J, Yigit S, Brauner R, Heinrich JJ, Cummings E, Riddell C, Enjalbert A \& Drouin J. Congenital isolated adrenocorticotropin deficiency: an underestimated cause of neonatal death, explained by TPIT gene mutations. Journal of Clinical Endocrinology and Metabolism 200590 1323-1331. (doi:10.1210/jc.2004-1300)

32 Scherbaum WA, Wass JA, Besser GM, Bottazzo GF \& Doniach D. Autoimmune cranial diabetes insipidus: its association with other endocrine diseases and with histiocytosis X. Clinical Endocrinology 198625 411-420. (doi:10.1111/j.1365-2265.1986.tb01707.x)

33 Nakahara R, Tsunekawa K, Yabe S, Nara M, Seki K, Kasahara T, Ogiwara T, Nishino M, Kobayashi I \& Murakami M. Association of antipituitary antibody and type 2 iodothyronine deiodinase antibody in patients with autoimmune thyroid disease. Endocrine Journal 200552 691-699. (doi:10.1507/endocrj.52.691)

34 Manetti L, Lupi I, Morselli LL, Albertini S, Cosottini M, Grasso L, Genovesi M, Pinna G, Mariotti S, Bogazzi F, Bartalena L \& Martino E. Prevalence and functional significance of antipituitary antibodies in patients with autoimmune and non-autoimmune thyroid diseases. Journal of Clinical Endocrinology and Metabolism 200792 2176-2181. (doi:10.1210/jc.2006-2748)

35 Hedstrand H, Ekwall O, Olsson MJ, Landgren E, Kemp EH, Weetman AP, Perheentupa J, Husebye E, Gustafsson J, Betterle C, Kampe O \& Rorsman F. The transcription factors SOX 9 and SOX10 are vitiligo autoantigens in autoimmune polyendocrine syndrome type I. Journal of Biological Chemistry 2001276 35390-35395. (doi:10.1074/jbc.M102391200)

36 Yamamoto M, Iguchi G, Takeno R, Okimura Y, Sano T, Takahashi M, Nishizawa H, Handayaningshi AE, Fukuoka H, Tobita M, Saitoh T, Tojo K, Mokubo A, Morinobu A, Iida K, Kaji H, Seino S, Chihara K \& Takahashi Y. Adult combined GH, prolactin, and TSH deficiency associated with circulating PIT-1 antibody in humans. Journal of Clinical Investigation 2011 121 113-119. (doi:10.1172/JCI44073)

37 Nishiyama M, Oshikawa K, Tsukada Y, Nakagawa T, Iemura S, Natsume T, Fan Y, Kikuchi A, Skoultchi AI \& Nakayama KI. CHD8 suppresses p53-mediated apoptosis through histone H1 recruitment during early embryogenesis. Nature Cell Biology 200911 172-182. (doi:10.1038/ncb1831)

38 Sudhof TC. The synaptic vesicle cycle: a cascade of protein-protein interactions. Nature $1995 \mathbf{3 7 5}$ 645-653. (doi:10.1038/ $375645 \mathrm{a} 0)$

39 Bean AJ, Zhang X \& Hokfelt T. Peptide secretion: what do we know? FASEB Journal 19948 630-638.

40 Vallet VS, Li JY \& Duval J. Secretogranin II (SgII) distribution and processing studies in human normal and adenomatous anterior pituitaries using new polyclonal antibodies. Regulatory Peptides 199768 155-163. (doi:10.1016/S0167-0115(96)02110-6)

41 Gerdes HH, Rosa P, Phillips E, Baeuerle PA, Frank R, Argos P \& Huttner WB. The primary structure of human secretogranin II, a widespread tyrosine-sulfated secretory granule protein that exhibits low $\mathrm{pH}$ - and calcium-induced aggregation. Journal of Biological Chemistry 1989264 12009-12015.

42 Spiwoks-Becker I, Maus C, tom Dieck S, Fejtova A, Engel L, Wolloscheck T, Wolfrum U, Vollrath L \& Spessert R. Active zone proteins are dynamically associated with synaptic ribbons in rat pinealocytes. Cell and Tissue Research 2008333 185-195. (doi:10. 1007/s00441-008-0627-3)

43 Mukherjee K, Yang X, Gerber SH, Kwon HB, Ho A, Castillo PE, Liu X \& Sudhof TC. Piccolo and bassoon maintain synaptic vesicle clustering without directly participating in vesicle exocytosis. PNAS 2010107 6504-6509. (doi:10.1073/pnas.1002307107)

44 Fujimoto K, Shibasaki T, Yokoi N, Kashima Y, Matsumoto M, Sasaki T, Tajima N, Iwanaga T \& Seino S. Piccolo, a Ca ${ }^{2+}$ sensor in pancreatic beta-cells. Involvement of cAMP-GEFII.Rim2.Piccolo complex in cAMP-dependent exocytosis. Journal of Biological Chemistry $2002 \quad 277 \quad 50497-50502 . \quad$ (doi:10.1074/jbc. M210146200)

45 Renden R, Berwin B, Davis W, Ann K, Chin CT, Kreber R, Ganetzky B, Martin TF \& Broadie K. Drosophila CAPS is an essential gene that regulates dense-core vesicle release and synaptic vesicle fusion. Neuron 200131 421-437. (doi:10. 1016/S0896-6273(01)00382-8)

46 Speidel D, Varoqueaux F, Enk C, Nojiri M, Grishanin RN, Martin TF, Hofmann K, Brose N \& Reim K. A family of $\mathrm{Ca}^{2+}$-dependent activator proteins for secretion: comparative analysis of structure, expression, localization, and function. Journal of Biological Chemistry $2003 \quad 278$ 52802-52809. (doi:10.1074/jbc. M304727200)

47 Ann K, Kowalchyk JA, Loyet KM \& Martin TF. Novel $\mathrm{Ca}^{2+}$-binding protein (CAPS) related to UNC-31 required for $\mathrm{Ca}^{2+}$-activated exocytosis. Journal of Biological Chemistry $1997 \mathbf{2 7 2}$ 19637-19640. (doi:10.1074/jbc.272.32.19637)

48 Grishanin RN, Kowalchyk JA, Klenchin VA, Ann K, Earles CA, Chapman ER, Gerona RR \& Martin TF. CAPS acts at a prefusion step in dense-core vesicle exocytosis as a PIP2 binding protein. Neuron 200443 551-562. (doi:10.1016/j.neuron.2004.07.028)

49 Tanaka S, Tatsumi K, Tomita T, Kimura M, Takano T, Yoshikawa $\mathrm{H} \&$ Amino N. Novel autoantibodies to pituitary gland specific factor $1 \mathrm{a}$ in patients with rheumatoid arthritis. Rheumatology 200342 353-356. (doi:10.1093/rheumatology/ $\operatorname{keg} 088$ )

Received 16 August 2011

Accepted 22 December 2011 